\title{
Development Activities of the High Heat Flux Scraper Element
}

\author{
J. Boscary ${ }^{\mathrm{a}}$, J. Lore ${ }^{\mathrm{b}}$, A. Lumsdaine ${ }^{\mathrm{b}}$, M. Maier ${ }^{\mathrm{a}}$, D. McGinnis ${ }^{\mathrm{b}}$, A. Peacock ${ }^{\mathrm{a}}$, J. Tretter ${ }^{\mathrm{a}}$ \\ ${ }^{a}$ Max Planck Institute for Plasma Physics, Garching, Germany \\ ${ }^{b}$ Oak Ridge National Laboratory, Oak Ridge, Tennessee, USA National Laboratory
}

\begin{abstract}
The function of the high heat flux scraper element is to reduce the heat loads on the element ends of the actively cooled divertor of Wendelstein 7-X. The scraper element is actively water cooled to remove up to $550 \mathrm{~kW}$ steady state power load, with localized heat fluxes as high as $20 \mathrm{MW} / \mathrm{m}^{2}$. Its surface area, $0.17 \mathrm{~m}^{2}$, is contoured to optimally intercept both upstream and downstream particle fluxes. The plasma facing surface is made of 24 individual scraper fingers based on the monoblock technology. Each scraper finger is $247 \mathrm{~mm}$ long and $28 \mathrm{~mm}$ wide and has 13 monoblocks made of CFC NB31 bonded by hot isostatic pressing onto a CuCrZr cooling tube equipped with a copper twisted tape. Development activities, described here, include the design and fabrication of prototypes to validate the different technologies selected for the scraper element design to prepare a possible production.
\end{abstract}

Keywords: Stellarator, Wendelstein 7-X, Plasma Facing Component, Divertor, Monoblock

\section{Introduction}

The stellarator Wendelstein 7-X (W7-X) is designed to operate with a stationary plasma for a pulse length of up to 30 minutes with $10 \mathrm{MW}$ cw (continuous wave) input power and peak power with additional heating systems of up to $24 \mathrm{MW}$ for $10 \mathrm{~s}$ [1,2]. W7-X is scheduled to start plasma operation in 2015. The first operation phase has a plasma duration $<1 \mathrm{~s}$ with up to 2 MW input power; an inertially cooled limiter made of graphite tiles is installed. The second operation phase has a plasma duration of 5-10 s with up to $8 \mathrm{MW}$ input power; an inertially cooled divertor is installed [3]. It will be replaced by the actively cooled divertor [4] to enable the full long pulse operation of the machine in 2019.

Recent plasma simulations showed that, for certain plasma scenarios in the long pulse operation mode, the evolution of the bootstrap current, which has a time constant of $\sim 40 \mathrm{~s}$, generates heat fluxes on the ends of the divertor target elements beyond their technological limits of $5 \mathrm{MW} / \mathrm{m}^{2}$ [5]. A scraper element is being investigated to reduce the heat loads at these locations by intercepting some of the particle fluxes before they reach the divertor surfaces. To confirm and validate the efficiency of the scraper element in long pulse operation, it has been recently decided to install an inertially cooled scraper element system during the second operation phase with the inertial divertor.

To prepare the possible fabrication of the high heat flux scraper element, development activities have been organized to produce prototypes to validate the different selected technologies.

\section{Scraper element design}

The magnetic configuration of W7-X has a five-fold toroidal symmetry leading to five field periods. Ten similar divertor units, two per field period, are located along the helical edge of the magnetic configuration which defines the W7-X geometry. Each divertor unit has 12 target modules, which are a set of target elements placed onto a support frame and actively water-cooled from manifolds.

The position and the shape of the scraper element have been optimized based on physics simulations for different bootstrap current evolutions [6]. The design of the scraper element is the result of an iterative process. It takes into account several constraints: technological limits for the heat loads, pumping efficiency in the divertor area, restricted available space, very limited possibility to adapt the neighboring components, in particular, the first wall components [7] which have already been installed in the vacuum vessel.

The scraper element is positioned in each of the ten divertor units outside the existing divertor volume in order as not to restrict pumping through the pumping gap defined by the divertor targets and the toroidal divertor closure (Fig. 1 and 2). Its $0.17 \mathrm{~m}^{2}$ surface is contoured to optimally intercept both upstream and downstream particle fluxes.

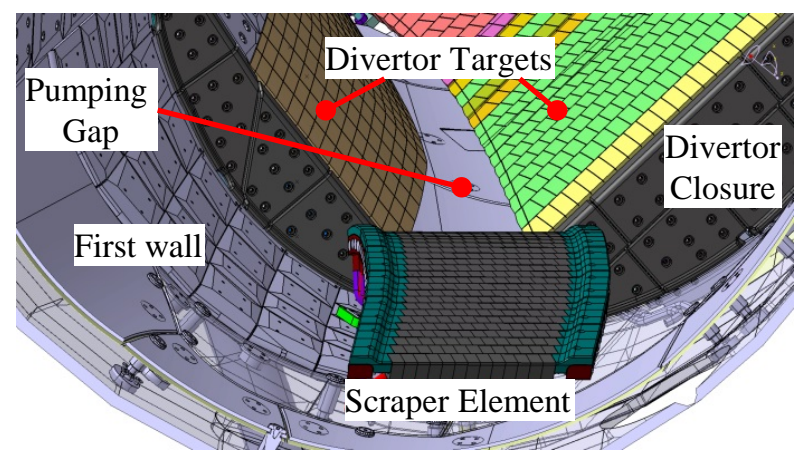

Fig. 1. Front view of the scraper element. 


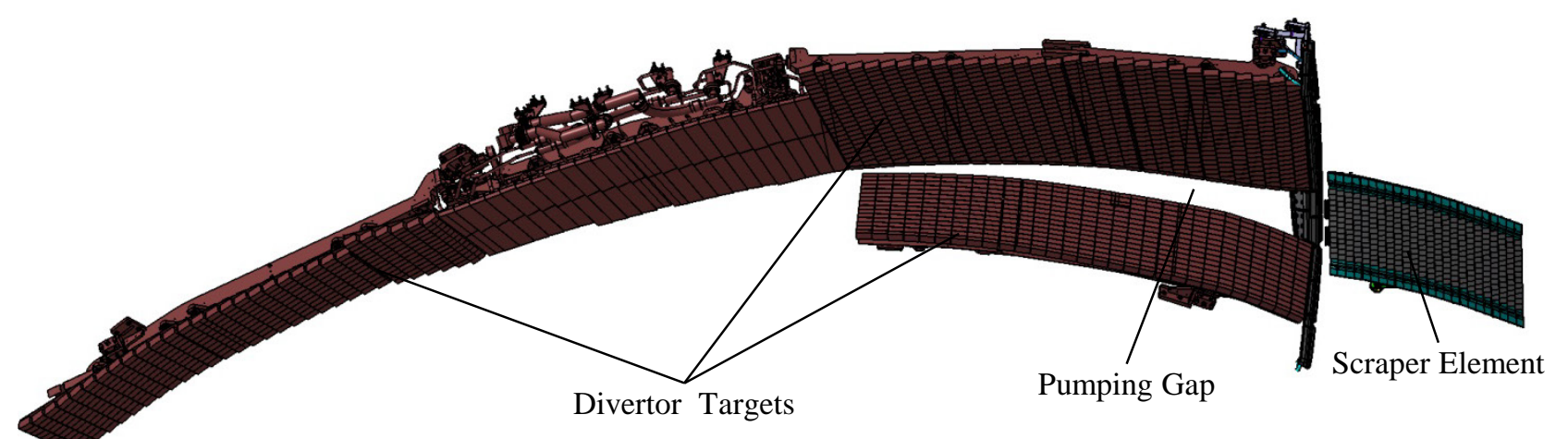

Fig. 2. Position of the scraper element (toroidal view).

The main components of the scraper element are shown in Fig. 3 and 4: 24 identical scraper fingers supported by a base plate, 3 connection legs to the vacuum vessel and the cooling system. The toroidal and poloidal length of the scraper element are 692 and 360 $\mathrm{mm}$, respectively. The vertical height without the connection legs varies between 128 and $145 \mathrm{~mm}$. The total dry weight is $48 \mathrm{~kg}$. The scraper fingers are oriented in the poloidal direction. A maximum step of $0.2 \mathrm{~mm}$ between two neighboring scraper fingers is allowed to take into account possible leading edge effects.

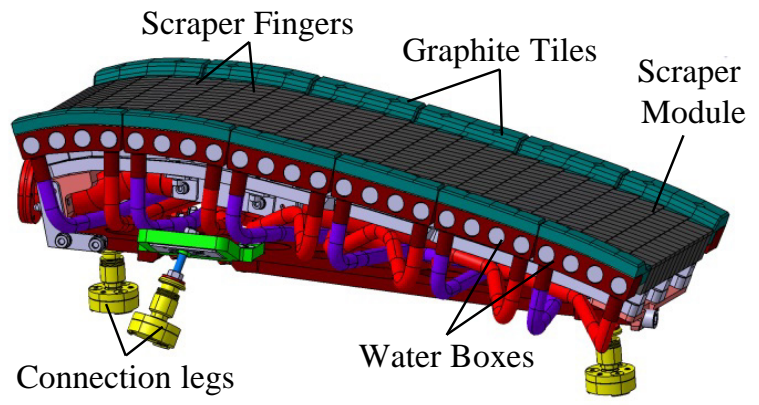

Fig. 3. View of a scraper element from the plasma side.

The 24 scraper fingers are divided into 6 sets of 4 and each set is defined as a scraper module. In each module, the 4 fingers are water-cooled in series and hydraulically connected to the water boxes, one for the inlet and one for the outlet. The 6 scraper modules are water-cooled in parallel and connected to two manifolds (inlet and outlet) located under the base plate.

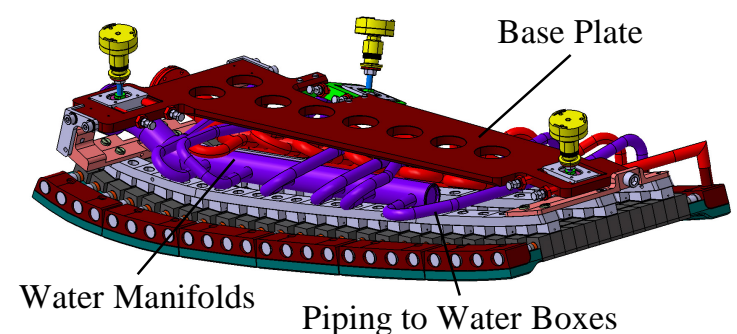

Fig. 4. View of a scraper element from the back side.
The hydraulic arrangement of the scraper fingers is based on simulations taking into account a maximum allowable pressure drop of 1.4 MPa for an axial velocity of $10-12 \mathrm{~m} / \mathrm{s}$ in the cooling channel of the finger [8]. The required flow rate for $12 \mathrm{~m} / \mathrm{s}$ in each scraper element is $26 \mathrm{~m}^{3} / \mathrm{h}$. The inlet pressure is the same as for the divertor, 2.8 MPa. The cooling system has been designed to remove a $550 \mathrm{~kW}$ steady state power load for each scraper element. The maximum allowable water temperature increase is $50 \mathrm{~K}$, with an inlet temperature of $20-30^{\circ} \mathrm{C}$. The manifolds are made of stainless steel and are protected against radiation loads, estimated to be up to $250 \mathrm{~kW} / \mathrm{m}^{2}$, with graphite tiles clamped with TZM screws. A graphite interlayer is placed between the top surface of the manifold and the graphite tiles to ensure a better thermal bonding.

\section{Scraper finger prototype}

The approach chosen for the design of the scraper finger uses, as far as possible, existing validated technology. The target elements of the W7-X divertor use flat tile technology and can withstand steady state heat fluxes of $10 \mathrm{MW} / \mathrm{m}^{2}$ [9]. Physics simulations have shown that localized heat fluxes as high as $20 \mathrm{MW} / \mathrm{m}^{2}$ will load the scraper element surface. As part of the development activities for the ITER divertor, CFC monoblock prototypes have been shown to survive 20 $\mathrm{MW} / \mathrm{m}^{2}$ [10-12]. Therefore, the monoblock technology has been selected for the scraper fingers.

A scraper finger is $247 \mathrm{~mm}$ long and $28 \mathrm{~mm}$ wide. The cross-sectional dimensions are indicated in Fig. 5. It has 13 monoblocks made of CFC NB31 bonded onto a CuCrZr cooling tube equipped with a copper twisted tape (Fig. 5). The inner diameter and the thickness of the cooling tube are $12 \mathrm{~mm}$ and $1.5 \mathrm{~mm}$, respectively. The thickness of the tape is $1 \mathrm{~mm}$ and the twist ratio 2 . The twist ratio defines the length to diameter ratio for an 180 ${ }^{\circ}$ twist. The CFC thickness between the cooling channel and the loaded surface has been dimensioned to give a maximum surface temperature of about $1200^{\circ} \mathrm{C}$. 


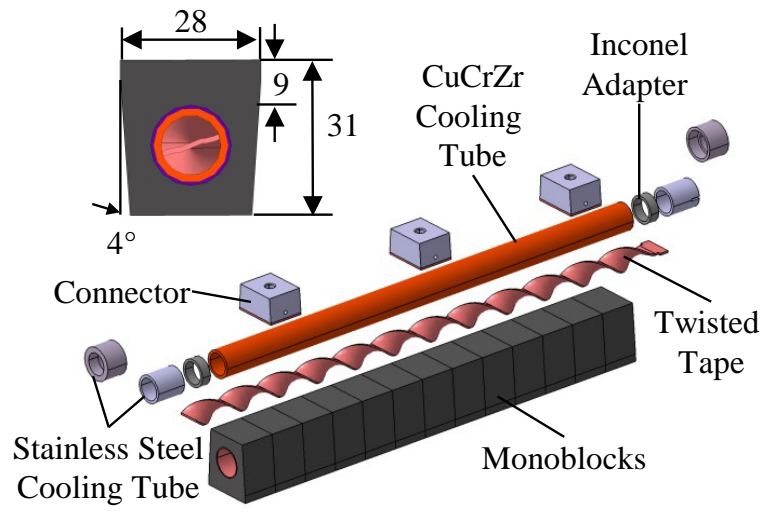

Fig. 5. Parts of the scraper finger (unit in $\mathrm{mm}$ )

Five full-scale prototypes are being manufactured by the Austrian company Plansee and will be delivered by the beginning 2015. The CFC monoblocks are prepared by active metal casting (AMC $®$ ) with an AMC layer of copper of $0.4 \mathrm{~mm}$. The bond between monoblocks and the cooling tube is made by hot isostatic pressing (HIP) at high temperature $\left(\sim 900^{\circ} \mathrm{C}\right)$. The same solution has been used for the bond between the 3 stainless steel connectors and the monoblocks. The CFC side of the 3 of the monoblocks have been prepared by AMC ${ }^{\circledR}$ of copper and joined by HIP. The two HIP operations have been performed at the same time. The transition between the CuCrZr and the stainless steel cooling tubes is made with an Inconel adapter, which is joined by electron beam welding. The mechanical properties of the $\mathrm{CuCrZr}$ material are recovered afterwards by appropriate heat treatment: $970^{\circ} \mathrm{C}$ for 1 hour followed by $475^{\circ} \mathrm{C}$ for 3 hours. The tape is mechanically attached with nuts machined in the stainless steel part. The completed scraper finger is shown in Fig.6.

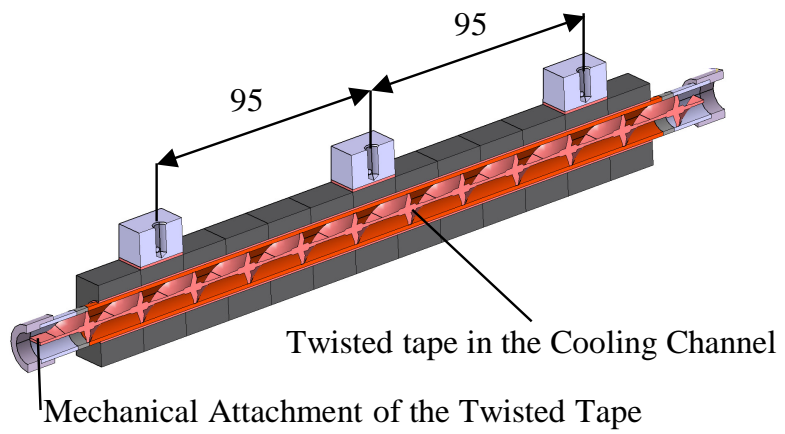

Fig. 6. Completed scraper finger (unit in mm)

The inspections systematically performed during the fabrication by the manufacturer are: visual inspection of the completed scraper finger, control of the bonding between the monoblocks and the cooling tube by thermography in the ARGUS facility [13], measurement of the pressure drop at the specified water velocity, control of the Helium leak rate under atmosphere and at room temperature.

The delivered components will also be inspected: visual inspection to ensure that no damages occurred during the transport, pressure drop measurements compared with the specification and the values measured by the manufacturer $( \pm 10 \%$ tolerance between measured and calculated values), control of the Helium leak rate at room temperature $\left(10^{-5} \mathrm{~Pa} . \mathrm{l} / \mathrm{s}\right)$. After the incoming inspections, the high heat flux performance and thermal fatigue resistance of the scraper finger prototypes will be tested in the Gladis facility [14]. During the tests, the evolution of the surface temperature is viewed by an infrared camera and will be compared to the calculated temperature.

\section{Scraper module prototype}

Due to the restricted available space, the design of the scraper element is very compact. The loaded surface geometry is defined by physics simulations and the first wall components are already installed. The result is a lack of space for the water-cooling system to remove high heat fluxes at high velocity. A prototype of one scraper module will be built and tested with the main objective of validating the design and the technology of the water boxes, and also the thermo-hydraulic simulations of the component under loading. The design of the prototype is shown in Fig. 7: 4 scraper fingers connected two water boxes, without Graphite tile protection. The support structure for testing is not shown.

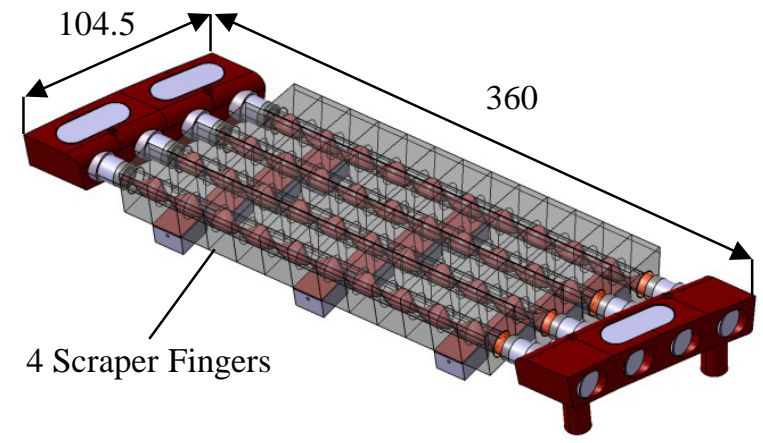

Fig. 7. Scraper module prototype. (unit in $\mathrm{mm}$ )

Before the fabrication of this prototype, an intermediate step has been planned to validate the water box concept. To avoid any damage to the scraper fingers, an intermediate simple prototype with stainless steel tubes has been designed, as shown in Fig. 8.

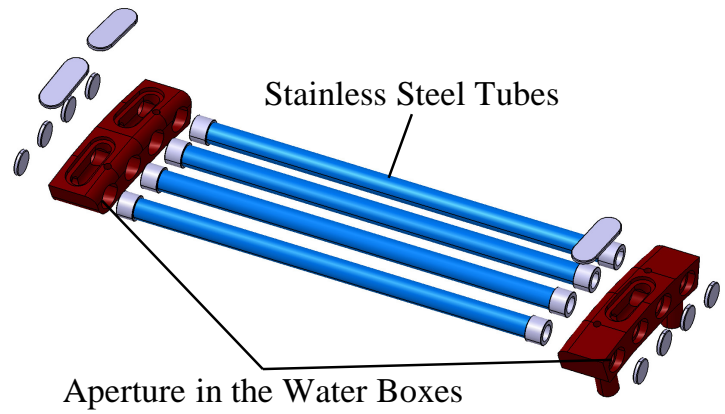

Fig. 8. Prototype for water boxes.

The challenge is to obtain a reliable connection between the cooling tube and the water box. The idea is to join them by orbital welding from the inside; the 
welding tool is installed and positioned from the apertures designed in the water boxes. This kind of technology has already been successfully used for the manifolds of the piping circuits of the first wall and of the high heat flux target modules of the divertor [15]. In addition the jigs for positioning and supporting the modules have to be installed in such a way that the scraper fingers are not damaged during the welding.

\section{Conclusion}

Recent plasma simulations indicate that, for certain plasma scenarios, bootstrap current evolution moves the strike points across the divertor targets and could thermally loads the divertor target ends beyond their acceptable limits. The aim of the scraper element is to reduce the heat loads at these locations by intercepting both upstream and downstream particle fluxes.

The position, shape and design of the scraper element are a trade-off between physics simulations and engineering constraints: maximum allowable local heat flux, cooling capability to remove the power loads in steady state, alignment tolerances and integration in a limited space. The development activities include the production and testing of prototypes to validate the design and the different selected technologies: mock-ups for the scraper fingers, the scraper module and the water boxes. The prototypes of the scraper fingers will be delivered and tested in the Gladis facility at the beginning of 2015, and the prototype of the scraper module in the last quarter of 2015.

The results of these activities will serve as a good basis to support a possible production and installation of the high heat flux scraper element during the full long pulse operation of W7-X.

\section{Acknowledgements}

This work was supported by the Federal Ministry of Education and Research of the Federal Republic of Germany under Grant 03FUS0014A. Only the authors are responsible for the content of this publication.

\section{References}

[1] M. Gasparotto et al., Wendelstein 7-X - Status of the project and commissioning planning, Fus. Eng. and Des. 89 (2014) 2121-2127.

[2] H. S. Bosch et al., Transition from construction to operation phase of the Wendelstein 7-X stellarator, IEEE Trans. on Plasma Sci. 42 (3) (2014) 432-438.

[3] A. Peacock et al., Progress in the design and development of a test divertor (TDU) for the start of W7-X operation, Fus. Eng. and Des. 84 (2009) 1475-1478.

[4] A. Peacock et al., Status of High Heat Flux Components at W7-X, IEEE Trans. on Plasma Sci. 42 (3) (2014) 524532.

[5] J. Boscary et al., Design improvement of the target elements of Wendelstein 7-X divertor, Fus. Eng. and Des. 87 (2012) 1453-1456.

[6] J. D. Lore et al., Design and analysis of divertor scraper elements for the W7-X stellarator, IEEE Trans. on Plasma Sci. 42 (3) (2014) 539-544.
[7] J. Boscary et al, Design and technological solutions for the plasma facing components of W7-X, Fus. Eng. and Des. 86 (2011) 572-575.

[8] A. Lumsdaine et al., Modeling and analysis of the W7-X high heat-flux divertor scraper element, IEEE Trans. on Plasma Sci. 42 (3) (2014) 545-551.

[9] J. Boscary et al., Summary of research and development activities for the production of the divertor target elements of Wendelstein 7-X, IEEE Trans. on Plasma Sci. 42 (3) (2014) 533-538.

[10] R. Tivey et al., ITER divertor, design issues and research and development, Fus. Eng. and Des. 46 (1999) 207-220.

[11] M. Missirlian et al., Results and analysis of high heat flux tests on a full-scale vertical target prototype of ITER divertor, Fus. Eng. and Des. 75-79 (2005) 435-440.

[12] M Richou et al., Assessment of CFC grades under thermal fatigue for the ITER inner vertical target, Phys. Scr. T145 (2011).

[13] H Traxler, P Schuler, Pulsed thermography inspection of the target elements for the W7-X divertor, Phys. Scr. T128 (2007) 242-245.

[14] H. Greuner et al., Design, performance and construction of a $2 \mathrm{MW}$ ion beam test facility for plasma facing components, Fus. Eng. and Des. 75-79 (2005) 345-350.

[15] B. Mendelevitch et al., Design analysis and manufacturing of the cooling lines of the in vessel components of W7-X, Fus. Eng. and Des. 86 (2011) 1669-1672. 